\title{
Caloric Intake, Dietary Lifestyles, Macronutrient Composition, and Alzheimer' Disease Dementia
}

\author{
Giulio Maria Pasinetti, ${ }^{1,2}$ Jun Wang, ${ }^{1}$ Shanee Porter, ${ }^{1}$ and Lap Ho ${ }^{1}$ \\ ${ }^{1}$ Department of Neurology, Mount Sinai School of Medicine, New York, NY 10029, USA \\ ${ }^{2}$ Geriatric Research, Education and Clinical Center, James J. Peters Veteran Affairs Medical Center, Bronx, NY 10468, USA
}

Correspondence should be addressed to Giulio Maria Pasinetti, giulio.pasinetti@mssm.edu

Received 1 December 2010; Accepted 12 May 2011

Academic Editor: Mikko Hiltunen

Copyright ( 2011 Giulio Maria Pasinetti et al. This is an open access article distributed under the Creative Commons Attribution License, which permits unrestricted use, distribution, and reproduction in any medium, provided the original work is properly cited.

Alzheimer's disease is a devastating neurodegenerative condition currently affecting over 5 million elderly individuals in the United States. There is much evidence suggesting that certain dietary lifestyles can help to prevent and possibly treat Alzheimer's disease. In this paper, we discuss how certain cardiovascular and diabetic conditions can induce an increased susceptibility for Alzheimer's disease and the mechanisms through which this occurs. We further discuss how the consumption of certain foods or food components can help to reduce one's risk for Alzheimer's disease and may possibly be developed as a therapeutic agent.

\section{Introduction}

Alzheimer's disease (AD) is a progressive neurodegenerative disorder characterized by a progressive decline in memory functions, which has become a growing public health concern. This condition of clinical dementia was first described by Alois Alzheimer in 1907, and ever since, the incidence of $\mathrm{AD}$ has increased exponentially. There are presently 5 million Americans affected with $\mathrm{AD}$, and the estimated annual health care cost is almost 100 billion dollars. Further, due to the expected increase in the number of individuals 65 years or older, it has been estimated that the total incidence of $\mathrm{AD}$ will quadruple by the year 2050 [1].

As there is presently no cure for this devastating condition, there is an urgent need to find a means of preventing, delaying the onset, or reversing the course of $\mathrm{AD}$. Recent research has provided evidence that certain dietary lifestyle choices can help to prevent Alzheimer's disease. This area of research has been quite exciting in light of the fact that delaying the onset of $\mathrm{AD}$ by just five years could cut its incidence in half.

In this paper, we first discuss the major pathological features of $\mathrm{AD}$ clinical dementia, followed by an examination of research on certain dietary factors that have been found to influence AD. These dietary factors include calorie, fat, and glucose/sugar intake, in addition to the inclusion of foods like fish, certain fruits and vegetables, plant extracts, spices and red wine, or polyphenol-rich foods in one's diet.

$\mathrm{AD}$ is pathologically characterized by the depositions of beta-amyloid aggregates in extracellular spaces and cerebral vasculatures as well as intracellular depositions of aggregated tau protein [2]. The "amyloid cascade hypothesis" is a popular model of $\mathrm{AD}$ pathogenesis and most of the autosomal dominant familial $\mathrm{AD}$ cases are caused by mutations in the amyloid precursor protein (APP), presenilin 1, or presenilin 2 , which lead to increased generation of beta-amyloid $(A \beta)$ peptides. However, the majority of the AD cases are sporadic. Cause(s) of sporadic AD are largely unknown. Multiple risk factors may contribute to the onset of sporadic AD. These risk factors include genetic risk factor such as the apolipoprotein E (APOE) genotype, as well as nongenetic and environmentally modifiable factors, including dietary, cardiovascular risk factors, physical and intellectual activities, and environment factors. As such, these factors have been generally considered as potential targets of intervention for $\mathrm{AD}$ prevention and therapy.

1.1. Alzheimer's Disease Neuropathology. AD is characterized in the brain by accumulated extracellular $\beta$-amyloid $(\mathrm{A} \beta)$ plaques and intracellular neurofibrillary tangles composed of 
abnormally hyperphosphorylated microtubular tau proteins. The manifestation of $\mathrm{AD}$ clinically is a progressive loss of cognitive abilities, including deficits in memory and planning. Neurotoxic $\mathrm{A} \beta$ is known to exist in multiple assembly states, which often result in varying pathophysiological effects. Additionally, although $\mathrm{A} \beta$ is classically understood to be deposited extracellularly, there is new evidence in mice and humans that $\mathrm{A} \beta$ peptides can also accumulate intraneuronally [3]. A $\beta$ species are generated from the ubiquitously expressed amyloid precursor protein (APP) through sequential proteolysis by $\beta$ - and $\gamma$-secretases [4-6]. Although the 40 -amino acid form of $\mathrm{A} \beta\left(\mathrm{A} \beta_{1-40}\right)$ is considered to be the major secreted species in $\mathrm{AD}$, the 42 -amino acid form of $\mathrm{A} \beta$ $\left(\mathrm{A} \beta_{1-42}\right)$, which contains two additional residues at its carboxyl terminus, is thought to initiate $\mathrm{AD}$ pathogenesis [7]. In addition, tau proteins in the brain (most particularly hyperphosphorylated tau), which aggregate into paired helical filaments and deposit as intracellular neurofibrillary tangles, $[8,9]$, are also considered to be a major pathology associated with Alzheimer's disease. Researchers posit that abnormal hyperphosphorylation of tau leads to the sequestration of normal and hyperphosphorylated tau in microtubules, leading to alternations in the healthy functioning of tau in the brain (including changes in axon transport and microtubule stability and polymerization $[10,11])$. As $\mathrm{A} \beta$ species and tau neurofibrillary tangles are the major hallmarks of $\mathrm{AD}$ neuropathology, research on therapies or preventions for $\mathrm{AD}$ are often geared toward attenuating or treating these neuropathologies.

In addition to $\mathrm{A} \beta$ and tau pathologies, mitochondrial functions also play a major role in $\mathrm{AD}$ clinical dementia [12]. Mitochondria regulate energy metabolism in cells and contribute largely to cell life or death (apoptosis). In the presence of increased $\mathrm{A} \beta$ content in the brain, mitochondria increase the generation of reactive oxygen species (ROS), which function as damaging agents and as signaling molecules. Highly reactive ROS, in fact, unleash a mechanism involving the liberation of cytochrome $c$, leading to neuronal apoptosis $[13,14]$. In human $\mathrm{AD}$ patients, positron emission tomography (PET) imaging assessments have suggested that the AD brain is characterized by impaired mitochondrial glucose metabolism, leading to neuronal hyperglycemic conditions [15]. In light of this evidence, controlling mitochondrial glucose/energy metabolism in the brain has also been of high interest to $\mathrm{AD}$ researchers for the prevention and treatment of $\mathrm{AD}$.

\section{Obesity and the Metabolic Syndrome in AD}

High-fat diets and sedentary lifestyles have become major concerns throughout the world. They have led to a growing incidence of obesity, dyslipidemia, high blood pressure, and hyperglycemic conditions, known collectively to be components of metabolic syndrome [16]. These health conditions are well known to develop along with, or be precursors of, atherosclerosis, cardiovascular disease, and diabetes. Recent studies have found that most of these disorders can also be linked to an increased risk of $\mathrm{AD}$. Of note, accumulating evidence suggests a mechanistic link between cholesterol metabolism in the brain and the formation of amyloid plaques in $\mathrm{AD}$ development $[17,18]$.

Epidemiological studies have demonstrated that individuals with obesity and diabetes have a fourfold increased risk for $\mathrm{AD}$. Health risks associated with obesity, including evidence that obesity may causally promote the AD degenerative process, are of high concern for public health. By the beginning of the twenty-first century, the fraction of Americans considered to be obese reached "epidemic" levels, according to a study published in [19]. This study, carried out between 1991 and 1998, observed a steady increase in weight in all 50 states, across genders, age groups, races, and educational levels, and occurring regardless of smoking status. This study found that obesity had increased from $12.0 \%$ in 1991 to $17.9 \%$ in 1998 . Likewise, national survey data has shown that between 1976-1980 and 1988-1994, the age-adjusted prevalence of obesity increased by 8 percentage points, from $14.5 \%$ to $22.5 \%$, in the US adult population ages $20-74$ years [20].

Several major studies have been conducted in humans to explore the relationship between obesity and the brain. Recently, Pannacciulli and colleagues [21] explored the association between body fat and regional alterations in brain structure using voxel-based morphometry (VBM) imaging (based on high-definition 3D magnetic resonance imaging [MRI]). Compared to lean subjects, obese individuals were found to have significantly lower gray matter density in the postcentral gyrus, frontal operculum, putamen, and middle frontal gyrus, indicating differences in the brain regulation of taste, reward and behavioral control. Additionally, Whitmer and colleagues [22] evaluated the possible association between obesity (as measured by body mass index (BMI) and skinfold thickness) in middle age and risk of dementia in later life in a large scale, multiethnic population-based cohort. Findings revealed that obese individuals (BMI > 30) in middle age had a $35 \%$ higher risk for dementia compared to normal weight individuals $(18.6<\mathrm{BMI}<24.9)$, independent of other comorbid conditions. Additionally, Balakrishnan and colleagues [23] investigated the association between blood plasma $\mathrm{A} \beta$ levels (which promote $\mathrm{AD}$ development), BMI, and fat mass (FM) in healthy adults and found significant correlations of BMI and FM with plasma $\mathrm{A} \beta_{1-42}$ levels and also noted that the presence of certain proteins known to play a role in inflammation, cardiovascular disease, and type 2 diabetes strengthened these correlations.

Researchers have also investigated the role of leptin, a protein hormone secreted in fat cells associated with obesity (which regulates appetite and metabolism), in AD pathogenesis. In pathological conditions of aging, such as in $\mathrm{AD}$, it has been demonstrated that the transport of leptin across the blood brain barrier (BBB) is significantly impaired, in particular, by the downregulation of megalin, a protein to which leptin must bind in order to enter the brain [24]. Leptin has also been shown to reduce $\beta$-secretase activity in neuronal cells, possibly by altering the lipid composition of membrane rafts, and thereby affecting $\mathrm{A} \beta$ generation. In fact, chronic administration of leptin actually reduced $\mathrm{A} \beta$ load in the brains of $\mathrm{AD}$ transgenic mice, suggesting the potential 
of leptin as a treatment for $\mathrm{AD}$ [25] and providing further support for the hypothesized link between obesity and AD.

\section{Calorie Intake and Caloric Restriction}

Research has demonstrated that caloric intake (among other nongenetic factors) influences one's risk for $\mathrm{AD}$, and, accordingly, that curbing obesity/calorie intake might play an important role in delaying the $\mathrm{AD}$ degenerative process. Clarifying the mechanisms through which caloric intake may ultimately influence AD neuropathology, and how caloric restriction (CR) may exert anti- $\beta$-amyloidogenic activities, may provide new avenues for designing preventive and/or therapeutic lifestyle strategies for AD and other neurodegenerative conditions.

The hypothesized preventive effects of $\mathrm{CR}$ on the development of mild cognitive impairment (MCI) or $\mathrm{AD}$ are supported by epidemiological evidence indicating that individuals who habitually consume fewer calories have a reduced incidence of $\mathrm{AD}[26,27]$. Additionally, studies have demonstrated that $\mathrm{CR}$ is one method by which one can mitigate the risk factor presented by elevated plasma homocysteine levels (which increase with age) for AD. Specifically, as high homocysteine levels render neurons to be more vulnerable by impairing DNA repair mechanisms (and thereby promoting cell death), lowering homocysteine levels through CR could potentially help to maintain the brain's neuroprotective abilities and help prevent against $\mathrm{AD}$ [28].

Halagappa and colleagues [29] tested the hypothesis that two different dietary energy restriction regimens- $-40 \%$ calorie restriction (CR) and intermittent fasting (IF) - could protect against cognitive decline in a transgenic mouse model of $\mathrm{AD}$ and found that both regimens ameliorated agerelated cognitive impairments but could not directly link the observed effects to $\mathrm{A} \beta$ and tau pathologies. Further, $\mathrm{Wu}$ and colleagues [30] investigated the effects of CR for 4 months on different $\mathrm{AD}$ phenotypes in another mouse model, finding that CR diets improved cognitive impairments in treated mice based on improved scores on assessments of novel object recognition and contextual fear conditioning memory. Further histological and biochemical analyses revealed that CR actually attenuated ventricle enlargement, caspace- 3 activation and astrogliosis and reduced the induction of tau hyperphosphorylation. Importantly, DNA microarray analysis in this study also demonstrated that CR could increase the expression of neurogenesis-related genes and decrease the expression of inflammation-related genes in the hippocampus of the mice, indicating that $\mathrm{CR}$ could induce neuroprotective activity in the brain.

In accordance with this line of work, we initiated a series of studies to investigate whether $\mathrm{AD}$ pathogenesis can be prevented by reducing calorie intake to levels appropriate for cardiac health. At the beginning of this endeavor, although evidence had supported a possible neuroprotective role of $\mathrm{CR}$ in neurodegeneration, there had been no information regarding whether $\mathrm{CR}$ could attenuate $\mathrm{AD}$ neuropathology until recently.
We explored whether a clinically acceptable weight reduction/CR regimen, based on an approximately 30\%reduced carbohydrate intake, could attenuate AD neuropathology and possibly mitigate preexisting amyloid neuritic pathology (by a reduction in plaque size) resulting in the recovery of amyloid-associated neuritic dystrophy as a function of time in Tg2576 AD-type mice [31]. In this study [32], 3-month old Tg2576 mice, which developed AD-type amyloid neuropathology at 8-10 months of age, were fed with a daily low-carbohydrate (low-carb) diet for 9 months, resulting in 30\% lower caloric intake compared to age- and gender-matched control mice fed ad libitum (AL) with a standard laboratory rodent diet (dietary content of protein, fat, cholesterol, vitamins, and minerals were identical across both mice groups). We found that the low-carb/CR diet in mice resulted in body weight stabilization, 3-fold lower ependymal fat pad weight, and improved glucose tolerance responses compared to the AL-fed mice at 9 months of age. This finding was consistent with clinical evidence indication that low-carb/CR diets considerably improve abnormal glucose control and obesity [33-35], which are risk factors for diabetes and $\mathrm{AD}[27,36]$. Moreover, when examined for $\mathrm{AD}$-type neuropathology, we found that the $\mathrm{CR}$ intervention almost completely prevented cortical and hippocampal $\mathrm{AD}$-type amyloid plaque (lower $\mathrm{A} \beta_{1-40}$ and $\mathrm{A} \beta_{1-42}$ concentrations) development relative to the AL-fed group. We next proceeded to explore APP processing and $A \beta$ peptide generation in the CR- and AL-fed mice, and, consistent with our previous evidence, we confirmed decreased levels of $\mathrm{A} \beta_{1-40}$ and $\mathrm{A} \beta_{1-42}$ in CR-fed compared to AL-fed mice. Further investigation revealed that $\gamma$-secretase activity had no involvement in the anti-amyloidogenic activity observed but that $\alpha$-secretase activity (which promotes the nonamyloidogenic processing of APP) likely played a role in the observed benefits of CR treatment in mice. As $\alpha$-secretase cleavage of APP is known to involve the release of a soluble and neuroprotective form of APP $(\operatorname{sAPP} \alpha)$, it is possible that CR may not only promote a non-amyloidogenic pathway in the brain, but also may promote brain repair activities as a result of sAPP $\alpha$ neurotrophic function [37].

Current therapeutic approaches to $\mathrm{AD}$ are aimed at preventing the generation of amyloidogenic $A \beta$ peptides, and for this reason, $\beta$ - and $\gamma$-secretase activities required for the formation of $A \beta$ peptides are central targets in the development of therapeutic agents in $\mathrm{AD}$ [38]. However, it has been difficult for scientists to find safe and selective $\beta$ - and $\gamma$-secretase inhibitors, as these activities are vital in the processing of other cellular substrates [38]. Our studies collectively revealed that $\mathrm{CR}$ dietary intervention benefitted $\mathrm{AD}$ mice by promoting $\alpha$-secretase activity, and thereby inhibiting the generation of high molecular weight $\mathrm{A} \beta$ peptides.

3.1. Sirtuins (SIRT1) in CR-Mediated AD Prevention. Sirtuins are class III histone deacetylases (HDAC) known as silent information regulators, which serve to catalyze deacetylation reactions in an $\mathrm{NAD}(+)$-dependent manner. Often called "longevity" genes, sirtuins regulate important cell functions by deacetylating histone and nonhistone targets. Activation of sirtuins is known to extend lifespan by promoting healthy 
aging in a variety of species and by protecting crucial tissues in the body, including those in the heart and brain. In mammalian systems, sirtuin activators protect against axonal degeneration, polyglutamine toxicity, and microgliamediated $A \beta$ toxicity, suggesting the potential therapeutic value of sirtuin activation in patients with $\mathrm{AD}$ [39]. SIRT1 has been found to protect against microglia-dependent $\mathrm{A} \beta$ toxicity by inhibiting NF- $\kappa \mathrm{B}$ signaling in the brain [40].

In 2006, we reported for the first time that promotion of SIRT1-mediated deacetylase activity may be a mechanism through which CR influences AD-type amyloid neuropathology. CR by $30 \%$ reduced carbohydrate intake was found to prevent amyloid neuropathology in young-adult Tg2576 mice, which may have been mediated in part through mechanisms involving activation of mammalian SIRT1 [41]. Consistent with this evidence in Tg2576 mice, we confirmed this finding in a new animal model by showing that a similar 30\% CR regimen in squirrel monkeys coincided with a significant reduction in $\mathrm{A} \beta_{1-40}$ and $\mathrm{A} \beta_{1-42}$ peptide content in the brain, which inversely correlated with the elevation of SIRT1 protein concentrations, relative to AL-fed monkeys [42]. In view of the fact that several studies in squirrel monkeys have been successfully used to provide important human physiological and biological information at organism, tissue, cellular, and molecular levels, these studies in squirrel monkeys strongly support our hypothesis that clinically applicable CR regimens in humans might be effective in preventing amyloid neuropathology and possibly MCI and AD.

Collectively, our studies on CR in AD mice and in squirrel monkeys revealed that certain experimental CR dietary regimens may promote, attenuate, or even partially reverse features of $\mathrm{AD}[32,41,42]$. In our studies, we found that high caloric intake, in particular of saturated fat, promotes ADtype $\beta$-amyloidosis and that reducing carbohydrate intake may actually prevent it, possibly through SIRT1-mediated response mechanisms.

\section{The Role of Insulin in AD}

Insulin and insulin signaling have been suggested to play a role the pathophysiology of $\mathrm{AD}[43,44]$. In population-based studies, individuals with type 2 diabetes mellitus are at an increased risk for cognitive impairment, dementia, and neurodegeneration. Mechanisms through which diabetes presents a risk factor include glycemia, insulin resistance, oxidative stress, advanced glycation endproducts, inflammatory cytokines, and microvascular and macrovascular disease [45]. The principal defect in type 2 diabetes is insulin resistance, leading to insulin deficiency. The islet of Langerhans (in the pancreas) in type 2 diabetes is characterized by $\beta$-cell loss and islet amyloid derived from islet amyloid polypeptide (IAPP) [46-48], a protein co-expressed and se-creted with insulin by $\beta$-cells. As with $\mathrm{A} \beta$ peptides, IAPP spontaneously forms into amyloid aggregates in an aqueous environment [49]. Additionally, as with $\mathrm{AD}$, the incidence of type 2 diabetes strongly increases with age. Borderline diabetes is also associated with increased risks of dementia and $\mathrm{AD}$, independent of whether one develops diabetes in later life, and may interact with severe systolic hypertension to multiply one's risk for Alzheimer's disease [50]. These findings implicate a close biological relationship between type 2 diabetes and AD.

In addition to complications affecting the eyes, kidneys, heart, blood vessels and nerves, diabetes mellitus is associated with damage to the central nervous system (CNS) and cognitive deficits $[51,52]$. Impairments in learning and memory have been documented in both types 1 and 2 diabetes. CNS deficits range from moderate to severe, depending on the quality of glycemic control, and involve mainly verbal memory and complex information processing [53-55]. Furthermore, it has been shown that insulin affects several brain functions including cognition and memory, and several studies have established links between insulin resistance, diabetes mellitus and $\mathrm{AD}$ [56]. Recent evidence indicates that insulin regulates the metabolism of $A \beta$ and tau proteins [57-59]. It has also been suggested that desensitization of neuronal insulin receptors and certain signaling events in $\mathrm{AD}$ could lead to reduced acetylcholine levels and cerebral blood flow, resulting in chronic and increasing deficits in oxidative metabolism [60]. Additionally, insulin is known to facilitate the hepatic clearance of plasma $\mathrm{A} \beta_{1-40}$ by intracellular translocation of low-density lipoprotein receptor-related protein 1 (LRP-1) to the plasma membrane in hepatocytes [61].

Alzheimer's disease (AD) is associated with major impairments in insulin and insulin-like growth factor (IGF) gene expression and signaling in the brain, which increase with severity of dementia and deficits in energy metabolism and acetylchoine homeostasis. This coexistence of insulin/ IGF deficiency and resistance in the brain suggests that $\mathrm{AD}$ may represent a brain-specific form of diabetes (i.e., type 3 diabetes). This hypothesis is supported by findings from de la Monte and colleagues [62] in an experimental animal model in which intracerebral streptozotocin (ic-STZ) was used to deplete brain, and not pancreatic, insulin. The icSTZ treatment produced brain-specific insulin depletion and insulin resistance and was associated with progressive neurodegeneration sharing many features in common with $\mathrm{AD}$. They demonstrated that early treatment with peroxisomeproliferator activated receptor agonists can effectively prevent ic-STZ-induced neurodegeneration and its associated deficits in learning and memory and that the observed effects were mediated by increased binding to insulin receptors, reduced levels of oxidative stress and tau phosphorylation, and increased choline acetyltransferase expression in the brain, suggesting potential therapeutic efficacy of insulin sensitizing agents in $\mathrm{AD}$.

4.1. Diabetogenic Diets and AD Amyloid Pathology. There is in vitro evidence that insulin itself may significantly promote the generation of extracellular amyloidogenic $\mathrm{A} \beta$ peptides through mechanisms that involve accelerated APP/A $\beta$ trafficking from the trans-Golgi network (a major cellular site for $\mathrm{A} \beta$ generation) to the plasma membrane [63]. While this evidence tentatively suggests that abnormal carbohydrate metabolism might play an important role in $\mathrm{AD}$ through mechanisms that involve $\mathrm{A} \beta$ peptide generation, experimental studies also suggest that insulin resistance may promote AD amyloid neuropathology in Tg2576 mice, possibly by 
limiting $\mathrm{A} \beta$ degradation via competition with insulin for degradation by the insulin-degrading enzyme (IDE) [64], a zincmetallopeptidase that preferentially cleaves proteins with a propensity to form $\beta$-pleated sheet-rich amyloid fibrils, such as monomeric $A \beta$ peptides [64].

Recent evidence suggests a role for insulin even in normal memory function, thereby supporting the hypothesis that insulin by itself affects mechanisms related to neuronal activity and cognitive function. Of particular interest to our research group, chronic hyperinsulinemia and insulin resistance, or reduced insulin effectiveness, has been demonstrated to negatively influence memory $[65,66]$. For example, Hoyer [60] proposed that low concentrations in circulating insulin in the CNS, along with reduced expression of insulin receptors and subsequent altered downstream signaling in $\mathrm{AD}$, would ultimately lead to reduced levels of acetylcholine and a corresponding decrease in cerebral blood flow.

Based on this evidence, and the fact that type 2 diabetes appears to be associated with an increased relative risk for $\mathrm{AD}[60,63,65-67]$, we recently explored in our laboratory the role of experimental type 2 diabetes in a Tg2576 mouse model of AD amyloid neuropathology. We found that a diabetogenic diet, resulting in elevated circulating levels of insulin, promoted amyloidogenic $\mathrm{A} \beta_{1-40}$ and $\mathrm{A} \beta_{1-42}$ peptide generation and amyloid plaque burden in the brain of Tg2576 mice. This also corresponded with increased $y$ secretase activities and decreased IDE activities. Moreover, the increased AD-type amyloid neuropathology also coincided with increased impairments in spatial memory function [68]. Further exploration of this interrelationship between insulin resistance and brain amyloidosis revealed a functional decrease in insulin receptor- (IR-) mediated signal transduction in the brain, as suggested by decreased IR $\beta$-subunit (IR- $\beta$ Y ${ }^{1162 / 1163}$ ) autophosphorylation and reduced phosphatidylinositol $3(\mathrm{Pl} 3)$-kinase/pS ${ }^{473}$-AKT/protein kinase- (PK-) B in these same brain samples [68]. This study collectively suggests that diet-induced insulin resistance in $\mathrm{AD}$ mice may significantly promote $\mathrm{AD}$-type amyloidosis in the brain through mechanisms involving the elevation of $\gamma$-secretase activity as a result of impaired IR signaling and also that type 2 diabetes may contribute to $A D$ amyloid pathology by attenuating the degradation of $A \beta$ peptide pathways associated with IDEs.

Interestingly, a later study by $\mathrm{Li}$ and colleagues [69] explored whether $\mathrm{AD}$-type pathological changes in the brain occur in two experimental rat models which develop type 1 and type 2 diabetes. They found accumulations of $\beta$-amyloid and phosphor-tau in these mice and that these pathologies were associated with neurite degeneration and neuronal loss. Changes in the rat model of type 2 diabetes were more severe and appeared to be associated with insulin resistance and possibly hypercholesterolemia. Additionally, Huang and colleages [70] found that compared to normal mice, a mouse model of hyperglycemia was more vulnerable to $\beta$-amyloid oxidative stress. These findings further support the role of insulin and insulin resistance in $\mathrm{AD}$ neuropathology and provide evidence that preventing diabetic conditions may in turn help to prevent $\mathrm{AD}$ dementia.

\section{Hypertension and AD}

Several studies have demonstrated an association between high blood pressure and $\mathrm{AD}$ [71-73]. It has been suggested that hypertension can increase one's risk for $\mathrm{AD}$ by potentially causing cerebrovascular disease or changes in blood vessel walls (which could lead to hypoperfusion, ischemia, and hypoxia), among other conditions, which can potentially initiate the pathological degenerative $\mathrm{AD}$ process. Additionally, subclinical $\mathrm{AD}$ has also been suggested as a risk factor for high blood pressure; thus, similar biological mechanisms may be involved in the pathogenesis of these two conditions [74].

The relationship between cognitive function and antihypertensive drug therapy has been investigated in several studies of hypertensive elderly human patients. For example, Guo and colleagues [75] found that a combination of certain calcium channel and $\beta$-adrenergic blockers used as antihypertensive agents protected elderly individuals from developing AD. Similarly, other studies have demonstrated that certain calcium channel blockers, such as dihydropyricine [76] and nitrendipine [77], decreased the incidence of $\mathrm{AD}$ in hypertensive individuals. Further, it has also been found that antihypertensive drugs that are $\mathrm{K}^{+}$-sparing diuretics, in particular, reduce the risk of $\mathrm{AD}$ in elderly individuals with hypertension [78]. Moreover, it was demonstrated that antihypertensive agents that cross the $\mathrm{BBB}$ and affect the renninangiotensin-aldosterone system (including perindopril or losartan), or brain calcium metabolism (like nitrendipine), provide additional protection against cognitive decline in addition to blood pressure control. All of these studies suggest a neuroprotective effect of certain antihypertensive agents.

In light of these findings, animal studies in our laboratory have shown that the application of certain antihypertensive drugs can improve cognition in animal models of AD. We conducted a high-throughput drug screening of 55 commercially available antihypertensive drugs and found 7 candidate agents that significantly reduced $\mathrm{AD}$-type $\mathrm{A} \beta$ accumulation in the brains of Tg2576 mice. Of these 7 drugs, we found that valsartan, an angiotensin receptor blocker, attenuated the oligomerization of $\mathrm{A} \beta$ into high-molecular-weight (HMW) oligomeric peptides (known to be involved in cognitive deterioration) in vitro and reduced the content of soluble HMW oligomeric $\mathrm{A} \beta$ in the brain in preventive studies. Additionally, we also found that valsartan, delivered at a dose 2-fold lower than the equivalent clinical dosage used in humans for hypertension, significantly attenuated the development of $\mathrm{A} \beta$-mediated cognitive deterioration [79]. Another in vitro study in this line of investigation revealed that the antihypertensive drugs furosemide, nitrendipine, and candesartan cilexetil prevented $\mathrm{A} \beta_{1-40}$ and $\mathrm{A} \beta_{1-42}$ oligomerization and that furosemide in particular dissociated preaggregated $\mathrm{A} \beta_{1-42}$ oligomers; follow-up studies revealed that short-term treatment with furosemide in $\mathrm{Tg} 2576$ mice resulted in reduced $\mathrm{A} \beta$ content in the brain [80]. Most recently, we have investigated the potential beneficial effects of carvedilol, a nonselective $\alpha / \beta$-adrenergic receptor blocker used to treat hypertension, on $\mathrm{AD}$ pathogenesis and treatment in two $\mathrm{AD}$ 
mouse models. We found that chronic oral treatment with carvedilol significantly attenuated brain contents of oligomeric $A \beta$ and cognitive deterioration in two mouse models of AD (the Tg2576 model of $\beta$-amyloidosis and TgCRND8 model of tauopathy), which coincided with improvements in neuronal transmission and the maintenance of less stable "learning" thin dendritic spines (associated with learning and memory functions) in the brains of these $\mathrm{AD}$ mice [81]. A related study in our laboratory investigated the benefits of carvedilol in $\mathrm{AD}$ on an electrophysiological parameter of learning and memory, long-term potentiation (LTP), as assessed in the TgCRND8 mouse model [82]. In this ex vivo study, hippocampal slices from carvedilol-treated TgCRND8 mice chronically treated with carvedilol showed improved basal neurotransmission and improved LTP, relative to slices from nontreated TgCRND8 mice, indicating that carvedilol improves neuroplasticity in this mouse model of AD.

Collectively, these studies suggest a clear link between hypertensive conditions and $\mathrm{AD}$ and, importantly, that antihypertensive agents may benefit $\mathrm{AD}$. In turn, these studies also indicate that taking dietary precautions to prevent hypertension may, in turn, reduce one's risk for $\mathrm{AD}$.

\section{The Link between Dietary Choices and AD}

A large area of research in the field of neurodegeneration has been focused on the role of specific foods and food components in the neurodegenerative process. Luchsinger et al. $[65,66]$ posited that taking nutritional supplements alone (e.g., carotenoids versus carrots) might not be as effective as whole foods in providing nutrients, perhaps because the interaction of nutrients within whole foods or certain dietary patterns might contribute largely to any food's benefit. As an example, one study [83] demonstrated that plantbased low-fat diets might be superior to low-fat diets containing little plant-based food intake (e.g., lower consumption of fruits, vegetables, nuts, etc.), even if the two diets have identical contents of fat, protein, carbohydrates, and cholesterol. The authors further noted that the beneficial effect of low-density lipoprotein (LDL) cholesterol in one's diet should not be underestimated.

One food of high interest in the AD prevention field has been fish. For example, researchers have investigated the benefits of certain omega-3 fatty acids found in fish and fish oils, specifically docosohexaenoic acid (DHA) and eicosapentaenoic acid, which have been shown to affect psychiatric and behavioral symptoms in $\mathrm{AD}$, as demonstrated in animal studies and in human epidemiological studies [84, 85]. In this line of research, Lim and colleagues [86] demonstrated that DHA-enriched diets significantly reduced AD-type amyloid neuropathology by approximately $70 \%$, including a decrease in $\mathrm{A} \beta_{1-42}$ levels, compared to low-DHA or control diets, in a mouse model of AD. Moreover, Hashimoto and colleagues [87] studied the effects of DHA on AD-type pathology following 12 weeks of DHA administration and found that DHA treatment led to a decreased number of working memory errors in $\mathrm{A} \beta$-infused rats in addition to an increase in corticohippocampal DHA levels and in the molar ratio of DHA/arachidonic acid, suggesting that DHA treatment attenuated impaired spatial cognition and learning abilities. They further demonstrated that DHA suppressed increases in levels of lipid peroxide and reactive oxygen species in the cerebral cortex and hippocampus of these $\mathrm{A} \beta$ infused rats, which suggested that DHA may also increase antioxidative defenses. These findings collectively demonstrated DHA's potential as a therapeutic agent in AD.

Another area of interest to researchers has been the benefits of certain plant extracts and spices in AD. In traditional Asian medicine, various leaves, fruits, barks, roots, and so forth have been used as agents to improve memory functions. In Ayurvedic medicine (a traditional system of Indian medicine), for example, Bacopa monnieri, Centella asiatica, Withania somnifera, Glycrrhiza glabra, Acorus calamus, and Emblica officinalis have been considered to enhance one's memory. Based on this notion, various laboratories have tested some of these memory-enhancing compounds in mouse models of AD. Mulberry leaf, for example, has been shown to inhibit $\mathrm{A} \beta_{1-42}$ fibril formation and protect hippocampal neurons from $\mathrm{A} \beta_{1-42}$-induced cell death in a concentration-dependent manner [88]. Additionally, in a screening of 27 herbs for their ability to protect $\mathrm{A} \beta_{1-42}$-induced neuronal death, Curcuma aromatia and Zingiber officinale (ginger) extracts were found to most effectively protect neurons. Several other herbs were also found to be neuroprotective (such as Ginkgo biloba (Ginkgo), Polygonatum sp. (King Solomon's seal), Cinnamum cassia (Chinese cinnamon), and Rheum coreanum (Korean rhubarb)), but did not exert as potent effects [89].

Ginkgo biloba extract in particular has been heavily investigated for its use as a preventive and therapeutic agent in $\mathrm{AD}$. It has been shown to exhibit neuroprotective effects in several mouse models [90] and improve cognitive function in $\mathrm{AD}$ patients $[91,92]$. Several studies have demonstrated the mechanisms by which Ginkgo biloba extract may benefit AD. For example, it has been shown to improve age-related memory deficits and $\mathrm{A} \beta$-peptide burden, act as a nitric oxide scavenger $[93,94]$, and regulate APP metabolism toward the $\alpha$-secretase pathway [95]. Ginkgo biloba extract has also been shown to inhibit $\mathrm{A} \beta$-induced free radical generation in a dose-dependent manner [96]. Further, Yao and colleagues [97] examined a specific Ginkgo biloba extract EGb761 in relation to cholesterol and amyloidogenesis and found that EGb761 treatment reduced APP and A $\beta$ generation coincidental with decreased levels of free circulating cholesterol in in vivo (in rats) and in vitro studies. Moreover, Lee and colleagues [98] investigated ginkgolides A and B for their effect on $\mathrm{A} \beta$-modulated acetylcholine release from hippocampal brain slices and found that ginkgolide $\mathrm{B}$ may produce antiamnestic effects by mitigating $\mathrm{A} \beta$ peptides' inhibitory effect on cholinergic transmission. These studies have provided evidence supporting further investigation of Ginkgo biloba extract in AD.

Another plant extract, curcumin, a polyphenolic yellow pigment in the turmeric spice used in Indian curries and in Indian herbal medicine, has been investigated for its potential use in $\mathrm{AD}$ prevention and therapy. Epidemiological studies demonstrated that the prevalence of $\mathrm{AD}$ in individuals 70-79 years of age is 4.4-fold less in the India compared 
to the U.S. [99]. The curcumin compound (1,7-bis(4-hydroxy-3-methoxyphenyl)-1,6 heptadiene-2,5 dione) has been shown to be neuroprotective against $\mathrm{A} \beta$ toxicity in vitro [100], antiamyloidogenic [101, 102], and capable of reducing brain amyloid load and plaque burden [103]. Spectrophotometric studies have suggested that curcumin binds to the more readily redox-reactive metals $\mathrm{Cu}$ and $\mathrm{Fe}$, but does not bind to $\mathrm{Zn}$, and, in turn, acts as an antioxidant by chelating the redox active metal ions in the body [104]. Lim and colleagues [105] found that dietary curcumin treatment in $\mathrm{AD}$ mice significantly lowered levels of oxidized proteins, interleukin-1 $\beta$ (a proinflammatory cytokine elevated in these mice), and insoluble and soluble $\mathrm{A} \beta$ in the brain and reduced amyloid plaque burden by $43 \%-50 \%$.

Several other spices have been investigated for their role in AD. For example, aged garlic extract has been shown in vitro to suppress the generation of reactive oxygen species, which are known to be involved in apoptosis as a result of $\mathrm{A} \beta$-mediated neurotoxicity [106], suggesting that garlic compounds may enhance antioxidant defenses in the brain. Additional in vitro evidence demonstrated that garlic treatment inhibits caspase- 3 in a dose-dependent manner, which indicates that garlic may inhibit apoptotic neuronal death in the brain [107]. Another spice of interest to researchers as been Crocus sativus, or saffron, due to its unusually polar carotenoid components. Notable, certain saffron extracts have been shown to inhibit $A \beta$ fibrillogenesis [108]. Further research on these extracts may illuminate precise mechanisms of action on $\mathrm{AD}$ neuropathology and their potential as preventive or therapeutic agents in $\mathrm{AD}$.

6.1. Fruit Juices and Wine. Polyphenols, the most abundant dietary antioxidants, have been heavily investigated for their ability to provide neuroprotection against oxidative damage in the brain. One study that propagated research on polyphenols in AD, conducted by Dai and colleagues [109], revealed that long-term fruit juice consumption can reduce one's risk for AD. The investigators suggested that the neuroprotective effects of fruit juices can be enhanced by consuming a combination of juices that are rich in phenolic compounds, which include juices derived from purple grapes, grapefruit, cranberries, and apples.

Several studies have examined the effects of certain fruit juices and extracts on AD. For example, apple juice was shown to prevent $\mathrm{A} \beta$-induced oxidative damage in vitro [110], and blueberry treatment has been found to reverse the effects of aging on motor behavior and neuronal signaling in animal models [111], possibly through mechanisms involving signal transduction, neuronal communication, and enhancement of hippocampal plasticity $[112,113]$. Moreover, treatment with antioxidant-rich pomegranate juice has been shown to reduce $A \beta_{1-42}$ content and amyloid deposition in the hippocampus by approximately $50 \%$ in mice. A study conducted by Mullen and colleagues [114] examined 13 different fruit juices and reported that purple grape juice contained the highest number of individual phenolic compounds in addition to the highest concentration of total phenolics. The main components found in purple grape juice, accounting for $93 \%$ of the total phenolic conent, were flavan- 3-ols, anthocyanins, and hydroxycinnamates. White grape juice, on the contrary, containing mainly hydroxycinnamates, had the lowest phenolic content of the juices examined.

Resveratrol is a naturally occurring polyphenol, found in the skin of grapes and red wine as a result of exposure to fungi or bacteria, which has been investigated for its ability to neuroprotect. Resveratrol has been demonstrated to maintain cell viability, exert antioxidant activity, exert proteasome-dependent antiamyloidogenic activity, and attenuate A $\beta$-induced cytotoxicity in PC12 cells in vitro [115-117]. Importantly, resveratrol is also understood to activate the expression of sirtuins, often referred to as the "longevity gene," in yeast [118] and in mammalian animal models of neurodegeneration $[119,120]$ — this resveratrol-induced sirtuin activation has been shown to promote neuroprotective activities against neuronal apoptosis. However, given recent evidence suggesting that resveratrol may not directly activate sirtuins [121], it is not quite clear if sirtuin activation plays a role in resveratrol's observed benefits in AD-type neuropathology. Further research will certainly illuminate resveratrol's bioactivity and the mechanisms through which it benefits $\mathrm{AD}$.

Several studies have suggested that moderate red wine consumption reduces the incidence of $\mathrm{AD}$ clinical dementia $[65,66,115,122-124]$ and may even benefit the course of $\mathrm{AD}$ [125]. Derived from red grapes, red wine is rich in antioxidants and holds neuroprotective properties. Studies in our laboratory, using an $\mathrm{AD}$ mouse model, examined whether moderate consumption of the red wine cabernet sauvignon (the most polyphenol-rich red wine, likely due to increased inclusion of grape skins) reduces $\mathrm{AD}$-type neuropathology and cognitive deterioration. We found that cabernet sauvignon treatment was capable of attenuating $\mathrm{AD}$-type cognitive deterioration and $\mathrm{A} \beta$ neuropathology by mechanisms involving nonamyloidogenic processing of APP, ultimately inhibiting $\mathrm{A} \beta$ generation $[126,127]$.

6.2. Grape Seed Polyphenolic Extract. Another area of investigation of high interest in the AD field has been the potential beneficial role of grape seed polyphenolic extract (GSPE) in attenuating $\mathrm{AD}$-type neuropathology and cognitive impairments. Studies in our laboratory have investigated a specific GSPE (MegaNatural), which is comprised primarily of catechin and epicatechin in monomeric, oligomeric, and polymeric forms, is readily absorbed through the intestinal mucosua due to modification of the constituent polyphenols in its preparation and has been demonstrated to be safe in animal models [128-131] and in humans with pre-hypertensive conditions [132]. In an initial investigation in a mouse model of $\mathrm{AD}$ [129], mice were treated for 5 months with $200 \mathrm{mg} / \mathrm{kg} /$ day GSPE in drinking water (equivalent to $1 \mathrm{~g} /$ day in humans, according to Food and Drug Administration criteria for converting drug dosages across species), after which in vitro and in vitro assessments were conducted at 6 (for behavior) and 10 (for neuropathology) months. In vitro studies revealed that GSPE prevented $\mathrm{A} \beta$ peptides from aggregating into high molecular weight (HMW) oligomers, and in vivo studies showed that GSPE treatment significantly 
reduced $A \beta_{1-40}$ and $A \beta_{1-42}$ peptide and HMW $A \beta$ oligomer levels and amyloid plaque burden in the brain, relative to ageand gender-matched water-treated mice. Moreover, GSPEtreated mice also performed significantly better tests of cognitive function compared to age- and gender-matched water treated mice. A follow-up mechanistic study [130] investigated in vitro GSPE's ability to alter the assembly of $\mathrm{A} \beta_{1-40}$ and $A \beta_{1-42}$ oligomers and $A \beta$-induced cytotoxicity in $A \beta$ treated PC12 cells; these studies revealed that GSPE blocked $\mathrm{A} \beta$ protofibril formation, preprotofibrillar oligomerization, and the structure transition from initial coil to $\alpha$-helix/ $\beta$ sheet. Additionally, GSPE exerted protective activities in assays of $\mathrm{A} \beta$-induced cytoxicity (prior to peptide assembly, following assembly, and just prior to peptide addition in cells). These studies collectively suggest a neuroprotective and possibly therapeutic role of GSPE in AD-type A $\beta$ neuropathology and cognitive deterioration.

To follow this line of work, we also investigated in vitro the potential beneficial role of GSPE on AD-type tau neuropathology [133], another major hallmark of AD. Using an in vitro model system, we found that GSPE treatment significantly inhibited the aggregation of tau peptides into filaments and was also capable of dissociating preformed tau aggregates. This finding suggests that GSPE treatment may attenuate deposits of tau aggregates in the $\mathrm{AD}$ brain.

In light of our evidence that GSPE was capable of attenuating $A \beta$ and tau pathology, we next explored GSPE bioavailability [131] to further assess its potential as an $\mathrm{AD}$ treatment. We found that acute oral administration of GSPE in Sprague Dawley rats led to detectable contents of catechin, epicatechin and their metabolites in the brain. Following repeated GSPE exposure, we detected accumulations of catechin, epicatechin, and gallic acid and their metabolites in the blood and similarly, catechin and epicatechin and their metabolites in the brain.

These studies, which demonstrate GSPE's ability to attenuate $\mathrm{AD}$-type $\mathrm{A} \beta$ pathology in vivo and in vitro and tau pathology in vitro, combined with its demonstrated safety and bioavailability, support the continued development of GSPE as a treatment for $\mathrm{A} \beta$ - and tau-mediated neurodegeneration and cognitive impairments.

\section{Conclusions and Future Trends}

Collectively, epidemiological and experimental research has demonstrated that dietary choices can play a key role in the prevention of $\mathrm{AD}$ and dementia. For example, much of the research described here suggest that preventing and managing conditions such as diabetes, hypertension, obesity, and heart disease may in turn prevent the onset of pathological aging and dementia. Research from our laboratory and others has demonstrated that reducing calorie intake can help prevent $\mathrm{AD}$ and similarly, given the demonstrated relationship between diabetogenic conditions and $\mathrm{AD}$, that preventing diabetes (perhaps by limiting one's glucose intake) may also decrease one's risk for AD. Moreover, studies have demonstrated that consuming foods that are rich in polyphenols, such as blueberries or grapes, may also prevent $\mathrm{AD}$ and cognitive deterioration, perhaps through their antioxidant and antiamyloidogenic activities. Based on the evidence described, it seems possible that in the near future, we may be able to utilize our knowledge of $\mathrm{AD}$ prevention through dietary changes and work toward intensive dietary intervention(s) that might be capable of preventing or treating $\mathrm{AD}$.

However, when reviewing this body of scientific literature, one must understand that this area of research is still in its infancy, and further research must be conducted before making any dietary recommendations to the general public for preventing neurodegenerative conditions of aging. For example, conditions such as $\mathrm{AD}$ are chronic and have a long latency period, and conducting clinical trials for dietary interventions under such circumstances, over long enough periods of time and on large enough samples to draw accurate and repeatable conclusions, would be a highly complex endeavor. Moreover, any dietary recommendations made toward this aim must always be incorporated into a general healthy diet. Future research on dietary lifestyles and their role in the prevention or treatment of dementia will certainly elucidate which diets and foods are capable of exerting neuroprotective activities, in what quantities, and by what mechanism(s) of action.

The current medical model for preventing and treating neurodegenerative conditions such as $\mathrm{AD}$ lacks a "whole organism" approach. For example, the onset of $\mathrm{AD}$ is likely a result of genomic and proteomic factors, but also psychosocial and lifestyle factors, such as nutrient intake or levels of stress. Today, Medicare and other insurers and individuals will pay billions of dollars for various surgical and medical procedures to treat chronic conditions (such as heart disease or diabetes), and yet they pay very little for integrative and preventive medicine approaches (such as alterations in diet) that can prevent or reverse many chronic conditions. By further investigating the role that dietary choices may play in $\mathrm{AD}$ and other dementias and diseases of aging, we will work toward the utilization of an integrative approach to medicine, taking into account all aspects of an individual's lifestyle when working toward the maintenance and curing of chronic diseases.

\section{References}

[1] R. Brookmeyer, S. Gray, and C. Kawas, "Projections of Alzheimer's disease in the United States and the public health impact of delaying disease onset," American Journal of Public Health, vol. 88, no. 9, pp. 1337-1342, 1998.

[2] D. J. Selkoe, "Alzheimer's disease: genes, proteins, and therapy," Physiological Reviews, vol. 81, no. 2, pp. 741-766, 2001.

[3] F. M. LaFerla, K. N. Green, and S. Oddo, "Intracellular amyloid- $\beta$ in Alzheimer's disease," Nature Reviews Neuroscience, vol. 8, no. 7, pp. 499-509, 2007.

[4] C. Haass, M. G. Schlossmacher, A. Y. Hung et al., "Amyloid $\beta$-peptide is produced by cultured cells during normal metabolism," Nature, vol. 359, no. 6393, pp. 322-325, 1992.

[5] M. Shoji, T. E. Golde, J. Ghiso et al., "Production of the Alzheimer amyloid $\beta$ protein by normal proteolytic processing," Science, vol. 258, no. 5079, pp. 126-129, 1992.

[6] J. Busciglio, D. H. Gabuzda, P. Matsudaira, and B. A. Yankner, "Generation of $\beta$-amyloid in the secretory pathway in 
neuronal and nonneuronal cells," Proceedings of the National Academy of Sciences of the United States of America, vol. 90, no. 5, pp. 2092-2096, 1993.

[7] T. E. Golde, C. B. Eckman, and S. G. Younkin, "Biochemical detection of $\mathrm{A} \beta$ isoforms: implications for pathogenesis, diagnosis, and treatment of Alzheimer's disease," Biochimica et Biophysica Acta-Molecular Basis of Disease, vol. 1502, no. 1, pp. 172-187, 2000.

[8] K. Mi and G. V. W. Johnson, "The role of tau phosphorylation in the pathogenesis of Alzheimer's disease," Current Alzheimer Research, vol. 3, no. 5, pp. 449-463, 2006.

[9] N. Sahara, S. Maeda, and A. Takashima, "Tau oligomerization: a role for tau aggregation intermediates linked to neurodegeneration," Current Alzheimer Research, vol. 5, no. 6, pp. 591-598, 2008

[10] M. D. Weingarten, A. H. Lockwood, S. Y. Hwo, and M. W. Kirschner, "A protein factor essential for microtubule assembly," Proceedings of the National Academy of Sciences of the United States of America, vol. 72, no. 5, pp. 1858-1862, 1975.

[11] G. Sorrentino and V. Bonavita, "Neurodegeneration and Alzheimer's disease: the lesson from tauopathies," Neurological Sciences, vol. 28, no. 2, pp. 63-71, 2007.

[12] P. Bubber, V. Haroutunian, G. Fisch, J. P. Blass, and G. E. Gibson, "Mitochondrial abnormalities in Alzheimer brain: mechanistic implications," Annals of Neurology, vol. 57, no. 5, pp. 695-703, 2005.

[13] M. J. Picklo Sr. and T. J. Montine, "Mitochondrial effects of lipid-derived neurotoxins," Journal of Alzheimer's Disease, vol. 12, no. 2, pp. 185-193, 2007.

[14] J. Viña, A. Lloret, S. L. Vallès et al., "Effect of gender on mitochondrial toxicity of Alzheimer's A $\beta$ peptide," Antioxidants and Redox Signaling, vol. 9, no. 10, pp. 1677-1690, 2007.

[15] A. P. Haley, J. Knight-Scott, V. I. Simnad, and C. A. Manning, "Increased glucose concentration in the hippocampus in early Alzheimer's disease following oral glucose ingestion," Magnetic Resonance Imaging, vol. 24, no. 6, pp. 715-720, 2006.

[16] J. M. Torpy, C. Lynm, and R. M. Glass, "JAMA patient page. The metabolic syndrome," Journal of the American Medical Association, vol. 295, no. 7, p. 850, 2006.

[17] I. J. Martins, E. Hone, J. K. Foster et al., "Apolipoprotein E, cholesterol metabolism, diabetes, and the convergence of risk factors for Alzheimer's disease and cardiovascular disease," Molecular Psychiatry, vol. 11, no. 8, pp. 721-736, 2006.

[18] P. C. Reid, Y. Urano, T. Kodama, and T. Hamakubo, "Alzheimer's disease: cholesterol, membrane rafts, isoprenoids and statins," Journal of Cellular and Molecular Medicine, vol. 11, no. 3, pp. 383-392, 2007.

[19] A. H. Mokdad, M. K. Serdula, W. H. Dietz, B. A. Bowman, J. S. Marks, and J. P. Koplan, "The spread of the obesity epidemic in the United States, 1991-1998," Journal of the American Medical Association, vol. 282, no. 16, pp. 1519 1522, 1999.

[20] K. M. Flegal and R. P. Troiano, "Changes in the distribution of body mass index of adults and children in the US population," International Journal of Obesity and Related Metabolic Disorders, vol. 24, no. 7, pp. 807-818, 2000.

[21] N. Pannacciulli, A. Del Parigi, K. Chen, D. S. N. T. Le, E. M. Reiman, and P. A. Tataranni, "Brain abnormalities in human obesity: a voxel-based morphometric study," NeuroImage, vol. 31, no. 4, pp. 1419-1425, 2006.

[22] R. A. Whitmer, E. P. Gunderson, E. Barrett-Connor, C. P. Quesenberry Jr., and K. Yaffe, "Obesity in middle age and future risk of dementia: a 27 year longitudinal population based study," British Medical Journal, vol. 330, no. 7504, pp. 1360-1362, 2005.

[23] K. Balakrishnan, G. Verdile, P. D. Mehta et al., "Plasma A $\beta 1$ 42 correlates positively with increased body fat in healthy individuals," Journal of Alzheimer's Disease, vol. 8, no. 3, pp. 269-282, 2005.

[24] M. O. Dietrich, C. Spuch, D. Antequera et al., "Megalin mediates the transport of leptin across the blood-CSF barrier," Neurobiology of Aging, vol. 29, no. 6, pp. 902-912, 2007.

[25] D. C. Fewlass, K. Noboa, F. X. Pi-Sunyer, J. M. Johnston, S. D. Yan, and N. Tezapsidis, "Obesity-related leptin regulates Alzheimer's A $\beta$," Journal of the Federation of American Societies for Experimental Biology, vol. 18, no. 15, pp. 18701878, 2004.

[26] J. A. Luchsinger, M. X. Tang, S. Shea, and R. Mayeux, "Caloric intake and the risk of Alzheimer disease," Archives of Neurology, vol. 59, no. 8, pp. 1258-1263, 2002.

[27] D. Gustafson, E. Rothenberg, K. Blennow, B. Steen, and I. Skoog, "An 18-year follow-up of overweight and risk of Alzheimer disease," Archives of Internal Medicine, vol. 163, no. 13, pp. 1524-1528, 2003.

[28] M. P. Mattson, "Will caloric restriction and folate protect against AD and PD?" Neurology, vol. 60, no. 4, pp. 690-695, 2003.

[29] V. K. M. Halagappa, Z. Guo, M. Pearson et al., "Intermittent fasting and caloric restriction ameliorate age-related behavioral deficits in the triple-transgenic mouse model of Alzheimer's disease," Neurobiology of Disease, vol. 26, no. 1, pp. 212-220, 2007.

[30] P. Wu, Q. Shen, S. Dong, Z. Xu, J. Z. Tsien, and Y. Hu, “Calorie restriction ameliorates neurodegenerative phenotypes in forebrain-specific presenilin-1 and presenilin-2 double knockout mice," Neurobiology of Aging, vol. 29, no. 10, pp. 1502-1511, 2008.

[31] K. Hsiao, P. Chapman, S. Nilsen et al., "Correlative memory deficits, $A \beta$ elevation, and amyloid plaques in transgenic mice," Science, vol. 274, no. 5284, pp. 99-102, 1996.

[32] J. Wang, L. Ho, W. Qin et al., "Caloric restriction attenuates $\beta$-amyloid neuropathology in a mouse model of Alzheimer's disease," Journal of the Federation of American Societies for Experimental Biology, vol. 19, no. 6, pp. 659-661, 2005.

[33] K. A. Meckling, C. O’Sullivan, and D. Saari, "Comparison of a low-fat diet to a low-carbohydrate diet on weight loss, body composition, and risk factors for diabetes and cardiovascular disease in free-living, overweight men and women," Journal of Clinical Endocrinology and Metabolism, vol. 89, no. 6, pp. 2717-2723, 2004.

[34] L. Stern, N. Iqbal, P. Seshadri et al., "The Effects of lowcarbohydrate versus conventional weight loss diets in severely obese adults: one-year follow-up of a randomized trial," Annals of Internal Medicine, vol. 140, no. 10, pp. 778-785, 2004.

[35] W. S. Yancy Jr., M. K. Olsen, J. R. Guyton, R. P. Bakst, and E. C. Westman, "A low-carbohydrate, ketogenic diet versus a low-fat diet to treat obesity and hyperlipidemia: a randomized, controlled trial," Annals of Internal Medicine, vol. 140, no. 10, pp. 769-777, 2004.

[36] M. Vanhanen and H. Soininen, "Glucose intolerance, cognitive impairment and Alzheimer's disease," Current Opinion in Neurology, vol. 11, no. 6, pp. 673-677, 1998. 
[37] S. Gandy, "Molecular basis for anti-amyloid therapy in the prevention and treatment of Alzheimer's disease," Neurobiology of Aging, vol. 23, no. 6, pp. 1009-1016, 2002.

[38] J. L. Cummings, "Alzheimer's disease," The New England Journal of Medicine, vol. 351, no. 1, pp. 56-57, 2004.

[39] L. Gan, "Therapeutic potential of sirtuin-activating compounds in Alzheimer's disease," Drug News and Perspectives, vol. 20, no. 4, pp. 233-239, 2007.

[40] J. Chen, Y. Zhou, S. Mueller-Steiner et al., "SIRT1 protects against microglia-dependent amyloid- $\beta$ toxicity through inhibiting NF- $\kappa \mathrm{B}$ signaling," Journal of Biological Chemistry, vol. 280, no. 48, pp. 40364-40374, 2005.

[41] W. Qin, T. Yang, L. Ho et al., "Neuronal SIRT1 activation as a novel mechanism underlying the prevention of alzheimer disease amyloid neuropathology by calorie restriction," Journal of Biological Chemistry, vol. 281, no. 31, pp. 21745-21754, 2006.

[42] W. Qin, M. Chachich, M. Lane et al., "Calorie restriction attenuates Alzheimer's disease type brain amyloidosis in Squirrel monkeys (Saimiri sciureus)," Journal of Alzheimer's Disease, vol. 10, no. 4, pp. 417-422, 2006.

[43] J. M. Burns, J. E. Donnelly, H. S. Anderson et al., "Peripheral insulin and brain structure in early Alzheimer disease," Neurology, vol. 69, no. 11, pp. 1094-1104, 2007.

[44] L. Li and C. Hölscher, "Common pathological processes in Alzheimer disease and type 2 diabetes: a review," Brain Research Reviews, vol. 56, no. 2, pp. 384-402, 2007.

[45] R. A. Whitmer, "The epidemiology of adiposity and dementia," Current Alzheimer Research, vol. 4, no. 2, pp. 117-122, 2007.

[46] G. J. S. Cooper, A. C. Willis, A. Clark, R. C. Turner, R. B. Sim, and K. B. M. Reid, "Purification and characterization of a peptide from amyloid-rich pancreases of type 2 diabetic patients," Proceedings of the National Academy of Sciences of the United States of America, vol. 84, no. 23, pp. 8628-8632, 1987.

[47] P. Westermark, C. Wernstedt, E. Wilander, D. W. Hayden, T. D. O'Brien, and K. H. Johnson, "Amyloid fibrils in human insulinoma and islets of Langerhans of the diabetic cat are derived from a neuropeptide-like protein also present in normal islet cells," Proceedings of the National Academy of Sciences of the United States of America, vol. 84, no. 11, pp. 3881-3885, 1987.

[48] K. H. Johnson, T. D. O’Brien, D. W. Hayden et al., "Immunolocalization of islet amyloid polypeptide (IAPP) in pancreatic beta cells by means of peroxidase-antiperoxidase (PAP) and protein A-gold techniques," American Journal of Pathology, vol. 130, no. 1, pp. 1-8, 1988.

[49] G. G. Glenner, E. D. Eanes, and C. A. Wiley, "Amyloid fibrils formed from a segment of the pancreatic islet amyloid protein," Biochemical and Biophysical Research Communications, vol. 155, no. 2, pp. 608-614, 1988.

[50] W. Xu, C. Qiu, B. Winblad, and L. Fratiglioni, "The effect of borderline diabetes on the risk of dementia and Alzheimer's disease," Diabetes, vol. 56, no. 1, pp. 211-216, 2007.

[51] W. H. Gispen and G. J. Biessels, "Cognition and synaptic plasticity in diabetes mellitus," Trends in Neurosciences, vol. 23, no. 11, pp. 542-549, 2000.

[52] D. Knopman, L. L. Boland, T. Mosley et al., "Cardiovascular risk factors and cognitive decline in middle-aged adults," Neurology, vol. 56, no. 1, pp. 42-48, 2001.

[53] C. M. Ryan, "Neurobehavioral complications of type I diabetes. Examination of possible risk factors," Diabetes Care, vol. 11, no. 1, pp. 86-93, 1988.
[54] M. W. J. Strachan, I. J. Deary, F. M. E. Ewing, and B. M. Frier, "Is type II diabetes associated with an increased risk of cognitive dysfunction? A critical review of published studies," Diabetes Care, vol. 20, no. 3, pp. 438-445, 1997.

[55] A. M. A. Brands, G. J. Biessels, E. H. F. De Haan, L. J. Kappelle, and R. P. C. Kessels, "The effects of type 1 diabetes on cognitive performance: a meta-analysis," Diabetes Care, vol. 28, no. 3, pp. 726-735, 2005.

[56] L. Gasparini, W. J. Netzer, P. Greengard, and H. Xu, "Does insulin dysfunction play a role in Alzheimer's disease?" Trends in Pharmacological Sciences, vol. 23, no. 6, pp. 288293, 2002.

[57] E. M. Mandelkow, G. Drewes, J. Biernat et al., "Glycogen synthase kinase-3 and the Alzheimer-like state of microtubuleassociated protein tau," Federation of European Biochemical Societies Letters, vol. 314, no. 3, pp. 315-321, 1992.

[58] D. C. Solano, M. Sironi, C. Bonfini, S. B. Solerte, S. Govoni, and M. Racchi, "Insulin regulates soluble amyloid precursor protein release via phosphatidyl inositol 3 kinase-dependent pathway," Journal of the Federation of American Societies for Experimental Biology, vol. 14, no. 7, pp. 1015-1022, 2000.

[59] L. Gasparini, G. K. Gouras, R. Wang et al., "Stimulation of $\beta$-amyloid precursor protein trafficking by insulin reduces intraneuronal $\beta$-amyloid and requires mitogen-activated protein kinase signaling," Journal of Neuroscience, vol. 21, no. 8, pp. 2561-2570, 2001.

[60] S. Hoyer, "The aging brain. Changes in the neuronal insulin/insulin receptor signal transduction cascade trigger late-onset sporadic Alzheimer disease (SAD)," Journal of Neural Transmission, vol. 109, no. 7-8, pp. 991-1002, 2002.

[61] C. Tamaki, S. Ohtsuki, and T. Terasaki, "Insulin facilitates the hepatic clearance of plasma amyloid $\beta$-peptide (140) by intracellular translocation of low-density lipoprotein receptor-related protein 1 (LRP-1) to the plasma membrane in hepatocytes," Molecular Pharmacology, vol. 72, no. 4, pp. 850-855, 2007.

[62] S. M. de la Monte, M. Tong, N. Lester-Coll, M. Plater Jr., and J. R. Wands, "Therapeutic rescue of neurodegeneration in experimental type 3 diabetes: relevance to Alzheimer's disease," Journal of Alzheimer's Disease, vol. 10, no. 1, pp. 89109, 2006.

[63] S. Craft and G. S. Watson, "Insulin and neurodegenerative disease: shared and specific mechanisms," The Lancet Neurology, vol. 3, no. 3, pp. 169-178, 2004.

[64] W. Farris, S. Mansourian, Y. Chang et al., "Insulin-degrading enzyme regulates the levels of insulin, amyloid $\beta$-protein, and the $\beta$-amyloid precursor protein intracellular domain in vivo," Proceedings of the National Academy of Sciences of the United States of America, vol. 100, no. 7, pp. 4162-4167, 2003.

[65] J. A. Luchsinger, M. X. Tang, S. Shea, and R. Mayeux, "Hyperinsulinemia and risk of Alzheimer disease," Neurology, vol. 63, no. 7, pp. 1187-1192, 2004.

[66] J. A. Luchsinger, M. X. Tang, M. Siddiqui, S. Shea, and R. Mayeux, "Alcohol intake and risk of dementia," Journal of the American Geriatrics Society, vol. 52, no. 4, pp. 540-546, 2004.

[67] R. P. Stolk, M. M. B. Breteler, A. Ott et al., "Insulin and cognitive function in an elderly population the rotterdam study," Diabetes Care, vol. 20, no. 5, pp. 792-795, 1997.

[68] L. Ho, W. Qin, P. N. Pompl et al., "Diet-induced insulin resistance promotes amyloidosis in a transgenic mouse model of Alzheimer's disease," Journal of the Federation of American Societies for Experimental Biology, vol. 18, no. 7, pp. 902-904, 2004. 
[69] Z. G. Li, W. Zhang, and A. A. F. Sima, "Alzheimer-like changes in rat models of spontaneous diabetes," Diabetes, vol. 56, no. 2, pp. 1817-1824, 2007.

[70] H. J. Huang, K. C. Liang, C. P. Chen, C. M. Chen, and H. M. Hsieh-Li, "Intrahippocampal administration of A $\beta 1-40$ impairs spatial learning and memory in hyperglycemic mice," Neurobiology of Learning and Memory, vol. 87, no. 4, pp. 483494, 2007.

[71] I. Skoog and D. Gustafson, "Hypertension, hypertensionclustering factors and Alzheimer's disease," Neurological Research, vol. 25, no. 6, pp. 675-680, 2003.

[72] K. M. Bellew, J. G. Pigeon, P. E. Stang, W. Fleischman, R. M. Gardner, and W. W. Baker, "Hypertension and the rate of cognitive decline in patients with dementia of the Alzheimer type," Alzheimer Disease and Associated Disorders, vol. 18, no. 4, pp. 208-213, 2004.

[73] F. C. Goldstein, A. V. Ashley, L. J. Freedman et al., "Hypertension and cognitive performance in African Americans with Alzheimer disease," Neurology, vol. 64, no. 5, pp. 899-901, 2005.

[74] I. Skoog and D. Gustafson, "Update on hypertension and Alzheimer's disease," Neurological Research, vol. 28, no. 6, pp. 605-611, 2006.

[75] Z. Guo, M. Viitanen, B. Winblad, and L. Fratiglioni, "Low blood pressure and incidence of dementia in a very old sample: dependent on initial cognition," Journal of the American Geriatrics Society, vol. 47, no. 6, pp. 723-726, 1999.

[76] J. M. López-Arrieta and J. Birks, "Nimodipine for primary degenerative, mixed and vascular dementia," Cochrane Database of Systematic Reviews, no. 3, Article ID CD000147, 2002.

[77] F. Forette, M. L. Seux, J. A. Staessen et al., "The prevention of dementia with antihypertensive treatment: new evidence from the systolic hypertension in Europe (syst-eur) study," Archives of Internal Medicine, vol. 162, no. 18, pp. 2046-2052, 2002.

[78] A. S. Khachaturian, P. P. Zandi, C. G. Lyketsos et al., "Antihypertensive medication use and incident Alzheimer disease: the Cache County Study," Archives of Neurology, vol. 63, no. 5, pp. 686-692, 2006.

[79] J. Wang, L. Ho, L. Chen et al., "Valsartan lowers brain $\beta$-amyloid protein levels and improves spatial learning in a mouse model of Alzheimer disease," Journal of Clinical Investigation, vol. 117, no. 11, pp. 3393-3402, 2007.

[80] W. Zhao, J. Wang, L. Ho, D. B. Teplow, and G. M. Pasinetti, "Identification of antihypertensive drugs which inhibit amyloid- $\beta$ protein oligomerization," Journal of Alzheimer's Disease, vol. 16, no. 1, pp. 49-57, 2009.

[81] J. Wang, K. Ono, D. L. Dickstein et al., "Carvedilol as a potential novel agent for the treatment of Alzheimer's disease," Neurobiology of Aging. In press.

[82] I. Arrieta-Cruz, J. Wang, C. Pavlides, and G. M. Pasinetti, "Carvedilol reestablishes long-term potentiation in a mouse model of Alzheimer's disease," Journal of Alzheimer's Disease, vol. 21, no. 2, pp. 649-654, 2010.

[83] C. D. Gardner, A. Coulston, L. Chatterjee, A. Rigby, G. Spiller, and J. W. Farquhar, "The effect of a plant-based diet on plasma lipids in hypercholesterolemic adults," Annals of Internal Medicine, vol. 142, no. 9, pp. 725-733, 2005.

[84] M. C. Morris, D. A. Evans, J. L. Bienias et al., "Consumption of fish and n-3 fatty acids and risk of incident Alzheimer disease," Archives of Neurology, vol. 60, no. 7, pp. 940-946, 2003.
[85] G. Young and J. Conquer, "Omega-3 fatty acids and neuropsychiatric disorders," Reproduction Nutrition Development, vol. 45, no. 1, pp. 1-28, 2005.

[86] G. P. Lim, F. Calon, T. Morihara et al., "A diet enriched with the omega-3 fatty acid docosahexaenoic acid reduces amyloid burden in an aged Alzheimer mouse model," Journal of Neuroscience, vol. 25, no. 12, pp. 3032-3040, 2005.

[87] M. Hashimoto, Y. Tanabe, Y. Fujii, T. Kikuta, H. Shibata, and O. Shido, "Chronic administration of docosahexaenoic acid ameliorates the impairment of spatial cognition learning ability in amyloid $\beta$-infused rats," Journal of Nutrition, vol. 135, no. 3, pp. 549-555, 2005.

[88] T. Niidome, K. Takahashi, Y. Goto et al., "Mulberry leaf extract prevents amyloid beta-peptide fibril formation and neurotoxicity," NeuroReport, vol. 18, no. 8, pp. 813-816, 2007.

[89] D. S. H. L. Kim, J. Y. Kim, and Y. S. Han, "Alzheimer's disease drug discovery from herbs: neuroprotectivity from $\beta$-amyloid (1-42) insult," Journal of Alternative and Complementary Medicine, vol. 13, no. 3, pp. 333-340, 2007.

[90] F. V. Defeudis, "Bilobalide and neuroprotection," Pharmacological Research, vol. 46, no. 6, pp. 565-568, 2002.

[91] B. S. Oken, D. M. Storzbach, and J. A. Kaye, "The efficacy of Ginkgo biloba on cognitive function in Alzheimer disease," Archives of Neurology, vol. 55, no. 11, pp. 1409-1415, 1998.

[92] P. L. Le Bars, F. M. Velasco, J. M. Ferguson, E. C. Dessain, M. Kieser, and R. Hoerr, "Influence of the severity of cognitive impairment on the effect of the Ginkgo biloba extract EGb 761@ in Alzheimer's disease," Neuropsychobiology, vol. 45, no. 1, pp. 19-26, 2002.

[93] S. Bastianetto, C. Ramassamy, S. Doré, Y. Christen, J. Poirier, and R. Quirion, "The Ginkgo biloba extract (EGb 761) protects hippocampal neurons against cell death induced by $\beta$-amyloid," European Journal of Neuroscience, vol. 12, no. 6, pp. 1882-1890, 2000.

[94] Y. Luo, J. V. Smith, V. Paramasivam et al., "Inhibition of amyloid- $\beta$ aggregation and caspase- 3 activation by the Ginkgo biloba extract EGb761," Proceedings of the National Academy of Sciences of the United States of America, vol. 99, no. 19, pp. 12197-12202, 2002.

[95] F. Colciaghi, B. Borroni, M. Zimmermann et al., "Amyloid precursor protein metabolism is regulated toward alphasecretase pathway by Ginkgo biloba extracts," Neurobiology of Disease, vol. 16, no. 2, pp. 454-460, 2004.

[96] Z. X. Yao, K. Drieu, and V. Papadopoulos, "The Ginkgo biloba extract EGb 761 rescues the PC12 neuronal cells from $\beta$-amyloid-induced cell death by inhibiting the formation of $\beta$-amyloid-derived diffusible neurotoxic ligands," Brain Research, vol. 889, no. 1-2, pp. 181-190, 2001.

[97] Z. X. Yao, Z. Han, K. Drieu, and V. Papadopoulos, "Ginkgo biloba extract (Egb 761) inhibits $\beta$-amyloid production by lowering free cholesterol levels," Journal of Nutritional Biochemistry, vol. 15, no. 12, pp. 749-756, 2004.

[98] T. F. Lee, C. F. Chen, and L. C. Wang, "Effect of ginkgolides on beta-amyloid-suppressed acetylocholine release from rat hippocampal slices," Phytotherapy Research, vol. 18, no. 7, pp. 556-560, 2004.

[99] M. Ganguli, V. Chandra, M. I. Kamboh et al., "Apolipoprotein E polymorphism and Alzheimer disease: the Indo-US cross- national dementia study," Archives of Neurology, vol. 57, no. 6, pp. 824-830, 2000.

[100] S. Shishodia, G. Sethi, and B. B. Aggarwal, "Curcumin: getting back to the roots," Annals of the New York Academy of Sciences, vol. 1056, pp. 206-217, 2005. 
[101] M. Y. Aksenov and W. R. Markesbery, "Changes in thiol content and expression of glutathione redox system genes in the hippocampus and cerebellum in Alzheimer's disease," Neuroscience Letters, vol. 302, no. 2-3, pp. 141-145, 2001.

[102] J. M. Ringman, S. A. Frautschy, G. M. Cole, D. L. Masterman, and J. L. Cummings, "A potential role of the curry spice curcumin in Alzheimer's disease," Current Alzheimer Research, vol. 2, no. 2, pp. 131-136, 2005.

[103] F. Yang, G. P. Lim, A. N. Begum et al., "Curcumin inhibits formation of amyloid $\beta$ oligomers and fibrils, binds plaques, and reduces amyloid in vivo," Journal of Biological Chemistry, vol. 280, no. 7, pp. 5892-5901, 2005.

[104] L. Baum and A. Ng, "Curcumin interaction with copper and iron suggests one possible mechanism of action in Alzheimer's disease animal models," Journal of Alzheimer's Disease, vol. 6, no. 4, pp. 367-377, 2004.

[105] G. P. Lim, T. Chu, F. Yang, W. Beech, S. A. Frautschy, and G. M. Cole, "The curry spice curcumin reduces oxidative damage and amyloid pathology in an Alzheimer transgenic mouse," Journal of Neuroscience, vol. 21, no. 21, pp. 83708377, 2001.

[106] Q. Peng, A. R. Buz'Zard, and B. H. S. Lau, "Neuroprotective effect of garlic compounds in amyloid- $\beta$ peptide-induced apoptosis in vitro," Medical Science Monitor, vol. 8, no. 8, pp. BR328-BR337, 2002.

[107] R. Jackson, B. McNeil, C. Taylor, G. Holl, D. Ruff, and E. T. Gwebu, "Effect of aged garlic extract on caspase-3 activity, in vitro," Nutritional Neuroscience, vol. 5, no. 4, pp. 287-290, 2002.

[108] M. A. Papandreou, C. D. Kanakis, M. G. Polissiou et al., "Inhibitory activity on amyloid- $\beta$ aggregation and antioxidant properties of Crocus sativus stigmas extract and its crocin constituents," Journal of Agricultural and Food Chemistry, vol. 54, no. 23, pp. 8762-8768, 2006.

[109] Q. Dai, A. R. Borenstein, Y. Wu, J. C. Jackson, and E. B. Larson, "Fruit and vegetable juices and Alzheimer's disease: the kame project," American Journal of Medicine, vol. 119, no. 9, pp. 751-759, 2006.

[110] D. Ortiz and T. B. Shea, "Apple juice prevents oxidative stress induced by amyloid-beta in culture," Journal of Alzheimer's Disease, vol. 6, no. 1, pp. 27-30, 2004.

[111] J. A. Joseph, N. A. Denisova, G. Arendash et al., "Blueberry supplementation enhances signaling and prevents behavioral deficits in an Alzheimer disease model," Nutritional Neuroscience, vol. 6, no. 3, pp. 153-162, 2003.

[112] F. C. Lau, B. Shukitt-Hale, and J. A. Joseph, "The beneficial effects of fruit polyphenols on brain aging," Neurobiology of Aging, vol. 26, pp. S128-S132, 2005.

[113] F. C. Lau, B. Shukitt-Hale, and J. A. Joseph, "Nutritional intervention in brain aging: reducing the effects of inflammation and oxidative stress," Subcellular biochemistry, vol. 42, pp. 299-318, 2007.

[114] W. Mullen, S. C. Marks, and A. Crozier, "Evaluation of phenolic compounds in commercial fruit juices and fruit drinks," Journal of Agricultural and Food Chemistry, vol. 55, no. 8, pp. 3148-3157, 2007.

[115] E. Savaskan, G. Olivieri, F. Meier, E. Seifritz, A. Wirz-Justice, and F. Müller-Spahn, "Red wine ingredient resveratrol protects from $\beta$-amyloid neurotoxicity," Gerontology, vol. 49, no. 6, pp. 380-383, 2003.

[116] J. H. Jang and Y. J. Surh, "Protective effect of resveratrol on $\beta$-amyloid-induced oxidative PC12 cell death," Free Radical Biology and Medicine, vol. 34, no. 8, pp. 1100-1110, 2003.

[117] P. Marambaud, H. Zhao, and P. Davies, "Resveratrol promotes clearance of Alzheimer's disease amyloid- $\beta$ peptides,"
Journal of Biological Chemistry, vol. 280, no. 45, pp. 3737737382, 2005.

[118] K. T. Howitz, K. J. Bitterman, H. Y. Cohen et al., "Small molecule activators of sirtuins extend Saccharomyces cerevisiae lifespan," Nature, vol. 425, no. 6954, pp. 191-196, 2003.

[119] T. Araki, Y. Sasaki, and J. Milbrandt, "Increased nuclear NAD biosynthesis and SIRT1 activation prevent axonal degeneration," Science, vol. 305, no. 5686, pp. 1010-1013, 2004.

[120] J. A. Parker, M. Arango, S. Abderrahmane et al., "Resveratrol rescues mutant polyglutamine cytotoxicity in nematode and mammalian neurons," Nature Genetics, vol. 37, no. 4, pp. 349-350, 2005.

[121] M. Pacholec, J. E. Bleasdale, B. Chrunyk et al., "SRT1720, SRT2183, SRT1460, and resveratrol are not direct activators of SIRT1," Journal of Biological Chemistry, vol. 285, no. 11, pp. 8340-8351, 2010.

[122] J. M. Orgogozo, J. F. Dartigues, S. Lafont et al., "Wine consumption and dementia in the elderly: a prospective community study in the Bordeaux area," Revista de Neurología, vol. 153, no. 3, pp. 185-192, 1997.

[123] A. Russo, M. Palumbo, C. Aliano, L. Lempereur, G. Scoto, and M. Renis, "Red wine micronutrients as protective agents in Alzheimer-like induced insult," Life Sciences, vol. 72, no. 21, pp. 2369-2379, 2003.

[124] F. Panza, V. Solfrizzi, A. M. Colacicco et al., "Mediterranean diet and cognitive decline," Public Health Nutrition, vol. 7, no. 7, pp. 1419-1425, 2004.

[125] N. Scarmeas, Y. Stern, R. Mayeux, and J. A. Luchsinger, "Mediterranean diet, alzheimer disease, and vascular mediation," Archives of Neurology, vol. 63, no. 12, pp. 1709-1717, 2006.

[126] J. Wang, L. Ho, Z. Zhao et al., "Moderate consumption of Cabernet Sauvignon attenuates $\mathrm{A} \beta$ neuropathology in a mouse model of Alzheimer's disease," Journal of the Federation of American Societies for Experimental Biology, vol. 20, no. 13, pp. 2313-2320, 2006.

[127] L. Ho, L. H. Chen, J. Wang et al., "Heterogeneity in red wine polyphenolic contents differentially influences Alzheimer's disease-type neuropathology and cognitive deterioration," Journal of Alzheimer's Disease, vol. 16, no. 1, pp. 59-72, 2009.

[128] S. S. Bentivegna and K. M. Whitney, "Subchronic 3-month oral toxicity study of grape seed and grape skin extracts," Food and Chemical Toxicology, vol. 40, no. 12, pp. 1731-1743, 2002.

[129] J. Wang, L. Ho, W. Zhao et al., "Grape-derived polyphenolics prevent $\mathrm{A} \beta$ oligomerization and attenuate cognitive deterioration in a mouse model of Alzheimer's disease," Journal of Neuroscience, vol. 28, no. 25, pp. 6388-6392, 2008.

[130] K. Ono, M. M. Condron, L. Ho et al., "Effects of grape seedderived polyphenols on amyloid $\beta$-protein self-assembly and cytotoxicity," Journal of Biological Chemistry, vol. 283, no. 47, pp. 32176-32187, 2008.

[131] M. G. Ferruzzi, J. K. Lobo, E. M. Janle et al., "Brain bioavailability of gallic acid and catechins is improved by repeated dosing in rats: implications for treatment in Alzheimer's disease," Journal of Alzheimer's Disease, vol. 18, no. 1, pp. 113-124, 2009.

[132] B. Sivaprakasapillai, I. Edirisinghe, J. Randolph, F. Steinberg, and T. Kappagoda, "Effect of grape seed extract on blood pressure in subjects with the metabolic syndrome," Metabolism, vol. 58, no. 12, pp. 1743-1746, 2009.

[133] L. Ho, S. Yemul, J. Wang, and G. M. Pasinetti, "Grape seed polyphenolic extract as a potential novel therapeutic agent in tauopathies," Journal of Alzheimer's Disease, vol. 16, no. 2, pp. 433-439, 2009. 


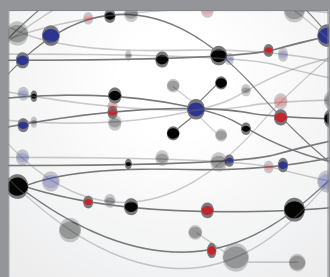

The Scientific World Journal
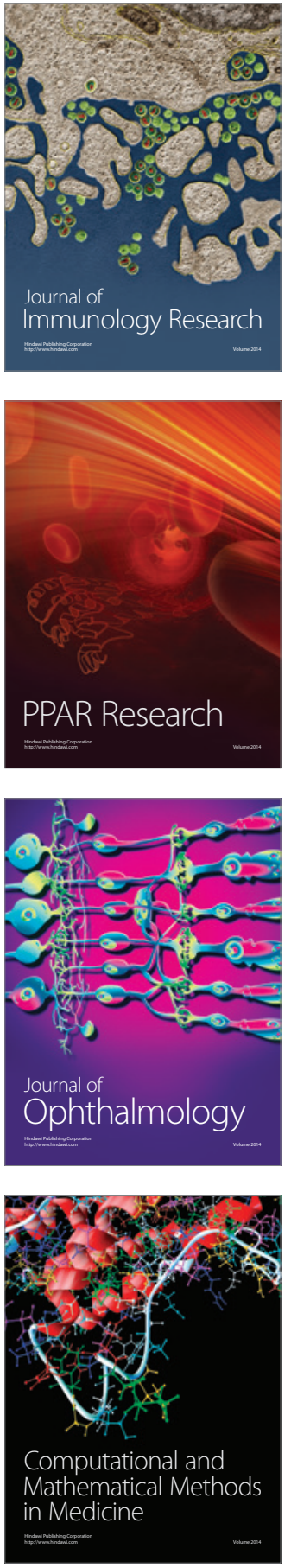

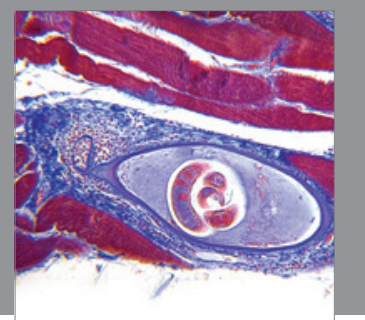

Gastroenterology

Research and Practice
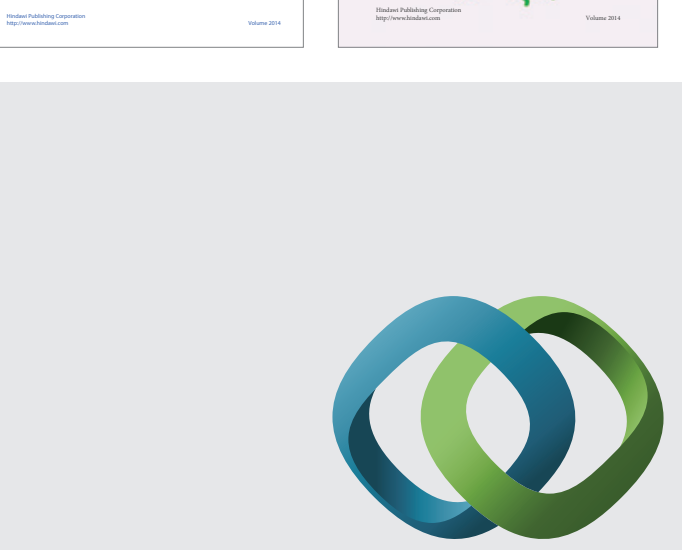

\section{Hindawi}

Submit your manuscripts at

http://www.hindawi.com
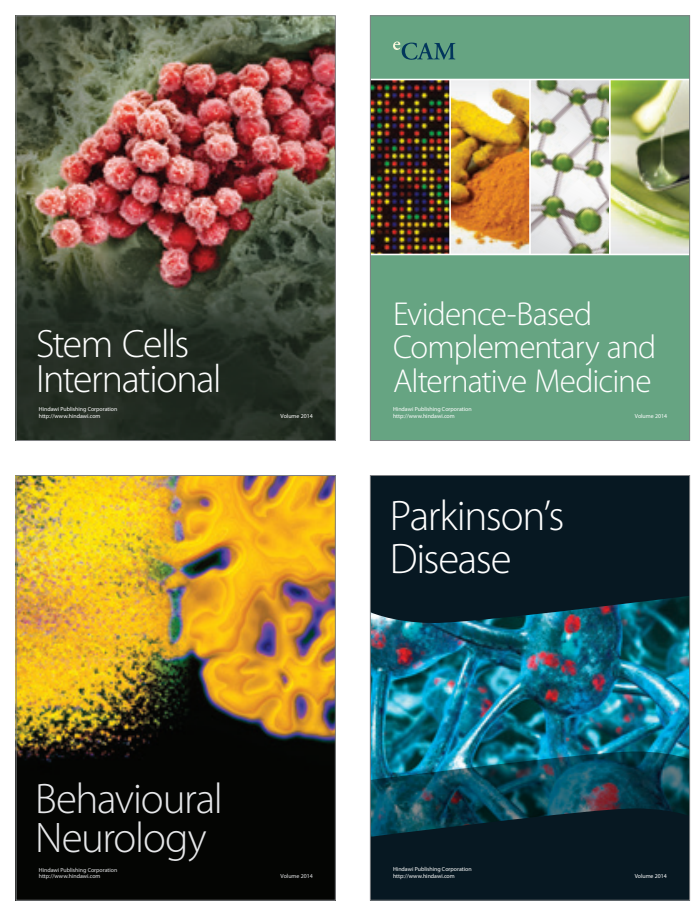

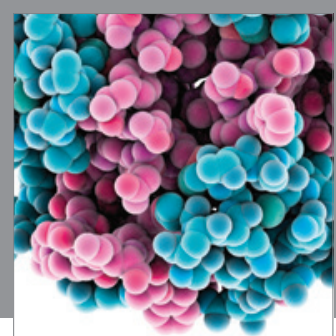

Journal of
Diabetes Research

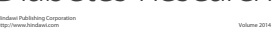

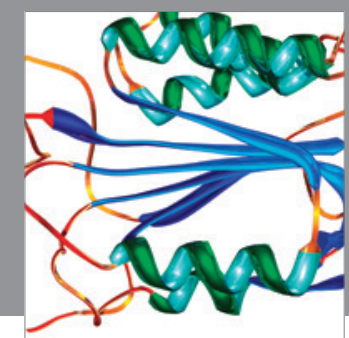

Disease Markers
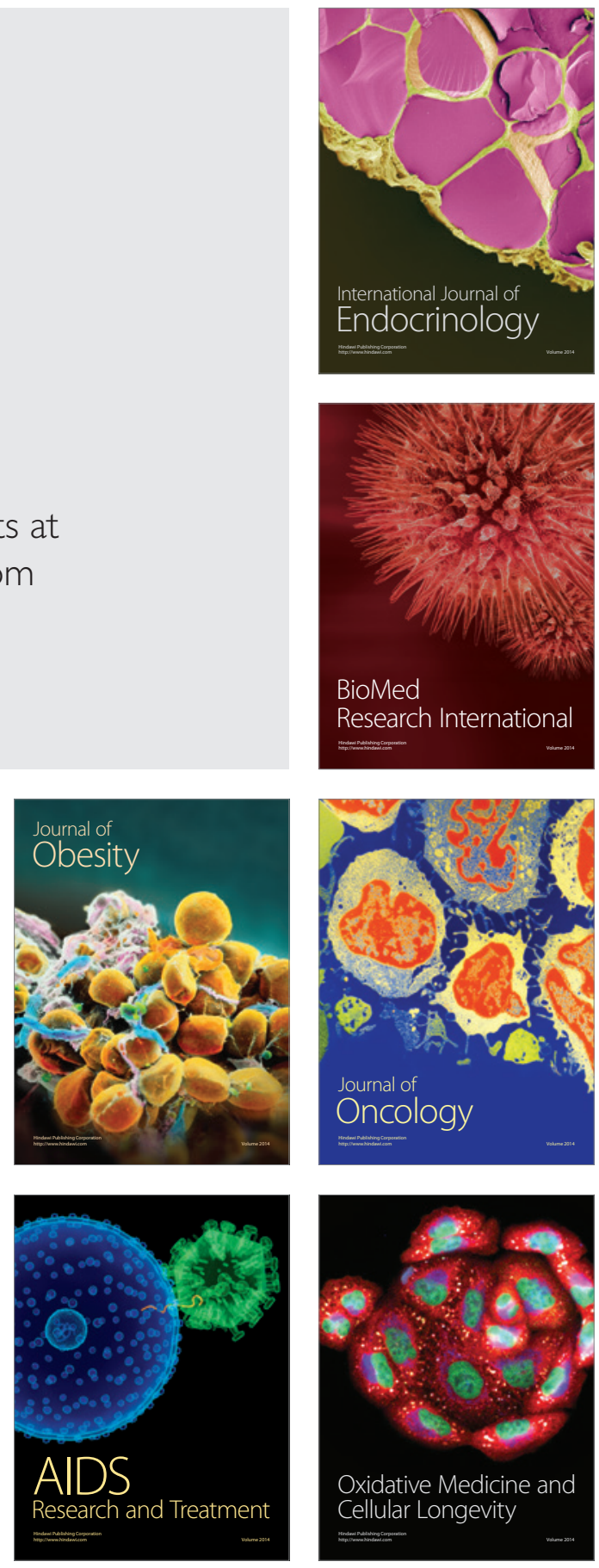